\title{
PENGARUH PROSES KEPERAWATAN BAGI KESEMBUHAN PASIEN
}

\author{
Nur Aini Lubis \\ Email: nrnlubis@gmail.com
}

\section{Latar Belakang:}

Proses keperawatan memberikan suatu pendekatan yang sistematis. Pada keperawatan kritis, harus menggunakan proses keperawatan dalam memberikan asuhan keperawatan.

Kualitas pelayanan keperawatan di rumah sakit tidak akan berjalan dengan baik apabila proses keperawatan yang dilaksanakan tidak terstruktur dengan baik. Pelayanan keperawatan merupakan bagian integral dari pelayanan kesehatan yang bisa menjadi tolak ukur keberhasilan dalam pencapaian tujuan suatu rumah sakit. Kualitas pelayanan keperawatan berjalan dengan baik apabila proses keperawatan yang dilaksanakan terstruktur dengan baik. Kualitas pelayanan ditentukan oleh manajemen asuhan keperawatan. Pelaksanakan asuhan keperawatan dengan menggunakan metode proses keperawatan untuk menyelesaikan masalah pasien, antara pasien dan perawat berhubungan secara langsung dalam pengelolaan asuhan keperawatan. . Departemen kesehatan RI menetapkan capaian standar asuhan keperawatan (SAK) yaitu sebesar 90\% (Depkes RI, 2010; Cheevakasemsook, 2006).

Tahap-tahap dalam proses Keperawatan adalah Pengkajian, Diagnosis Keperawatan, Perencanaan,Pelaksanaan dan Evaluasi.

\section{Metode}

Metode yang digunakan adalah metode survey dengan pendekatan kuantitatif. Dengan jumlah sampel 30 responden. Metode pengumpulan data melalui kuesioner dan observasi langsung.

\section{Pembahasan}

Pengkajian keperawatan adalah proses pengumpulan, pengujian, analisa, dan mengkomunikasikan data tentang klien. Tujuan pengkajian untuk membuat data dasar tentang tingkat kesehatan klien, praktik kesehatan, penyakit terdahulu, dan pengalaman yang berhubungan, dan tujuan perawatan kesehatan. Status pasien akan mengatur waktu dan kedalaman pengkajian. Pengkajian menghasilkan data dasar. Data dasar ini dirumuskan dari riwayat keperawatan, pengkajian fisik, dan sumber lain dari pengkajian data. Dibutuhkan pengkajian yang komprehensif untuk mengidentifikasikan kebutuhan pasien saat ini, 
antisipasi kebutuhan yang akan datang membuat keputusan dan melakukan dan melakukan koordinasi tindak lanjut perawatan.

Diagnosis keperawatan merupakan penilaian klinis terhadap pengalaman atau respon individu,keluarga, dan komunitas pada masalah kesehatan pada resiko masalah kesehatan atau pada proses kehidupan. Diagnosis keperawatan merupakan bagian vital dalam menentukan asuhan keperawatan yang sesuai untuk membantu klien mencapai kesehatan yang optimal.

Asuhan keperawatan adalah faktor penting dalam kelangsungan hidup pasien dan aspek-aspek pemeliharaan, rehabilitatif dan prefentif perawatan kesehatannya. Menurut Shore, untuk sampai pada hal ini, profesi keperawatan telah mengidentifkasi proses pemecahan masalah yang "menggabungkan elemen yang paling diinginkan dari seni keperawatan dengan elemen yang paling relevan dari sistem teori, dengan menggunakan metode ilmiah". Proses keperawatan ini diperkenalkan pada tahun 1950-an sebagai proses yang terdiri atas tiga tahap : Pengkajian, perencanaan dan evaluasi yang didasarkan pada metode ilmiah pengamatan, pengukuran, pengumpulan data dan penganalisaan temuan.

Kajian selama bertahun-tahun, penggunaan dan perbaikan telah mengarahkan perawat pada pengembangan proses keperawatan menjadi lima langkah yang konkret (pengkajian, identifikasi masalah, perencanaan, implementasi dan evaluasi) yang memberikan metode efisien tentang pengorganisasian proses berfikir untuk pembuatan keputusan klinis.

Menurut Peter dan Olson (2000), kepuasan pelanggan adalah konsep penting dalam konsep pemasaran dan penelitian konsumen. Menurut Kotler dan Keller (2009), kepuasan pelanggan (customer satisfaction) diartikan sebagai fungsi dari seberapa sesuainya harapan pembeli produk dengan kinerja yang dipikirkan pembeli atas produk tersebut. Westbrook dan Reilly juga memberikan definisi atau pengertian kepuasan pelanggan (customer satisfaction) sebagai respons emosional terhadap pengalamanpengalaman berkaitan dengan produk atau jasa tertentu yang dibeli, gerai ritel, atau bahkan pola perilaku (seperti perilaku berbelanja dan perilaku pembeli), serta pasar secara keseluruhan (dalam Tjiptono 2008).

1. Pengaruh Pengkajian Terhadap Kepuasan Pasien

pengkajian berpengaruh positif dan signifikan terhadap kepuasan pasien semakin baik optimal pengkajian keperawatan yang dilakukan maka kepuasan pasien akan semakin meningkat.

Pengkajian merupakan tahap awal dan dasar utama dari proses keperawatan. Tahap pengkajian terdiri atas pengumpulan data dan perumusan kebutuhan atau masalah klien. Data 
yang dikumpulkan meliputi data biologis, psikologis, sosial dan spiritual. Kemampuan perawat yang diharapkan dalam melakukan pengkajian adalah mempunyai kesadaran/ tilik diri, kemampuan mengobservasi dengan akurat, kemampuan berkomunikasi terapeutik dan senantiasa mampu berespons secara aktif

\section{Pengaruh Diagnosa Terhadap Kepuasan Pasien}

Diagnosis keperwatan memberikan gambaran tentang masalah atau status kesehatan klien yang nyata (aktual) dan kemungkinan akan terjadi,dimana pemecahannya dapat dilakukan dalam batas wewenang perawat.

Diagnosa keperawatan ini merupakan bentuk dari pelayanan yang dilakukan oleh perawat yang sesuai dengan wewenang perawat. Kesalahan dalam mendiagnosa juga tentu dapat merugikan pasien. Kepuasan dari pasien ini sangat berpengaruh nantinya terhadap penilaian orang lain terhadap kualitas rumah sakit.

\section{Pengaruh Intervensi Terhadap Kepuasan Pasien}

Intervensi (Rencana tindakan keperawatan) merupakan serangkaian tindakan yang dapat mencapai tiap tujuan khusus. Perencanaan keperawatan meliputi perumusan tujuan, tindakan dan penilaian rangkaian asuhan keperawatan pada klien berdasarkan analisis pengkajian agar masalah kesehatan dan keperawatan klien dapat diatasi.

Rencana tindakan disesuaikan dengan standar asuhan keperawatan Amerika yang membagi karakteristik tindakan berupa : tindakan konseling, pendidikan kesehatan, perawatan mandiri dan aktivitas hidup sehari-hari, terapi modalitas keperawatan, perawatan berkelanjutan, tindakan kolaborasi (terapi somatik dan psikofarma). Pada dasarnya tindakan keperawatan terdiri dari tindakan observasi dan pengawasan, terapi perawatan, pendidikan kesehatan dan tindakan kolaborasi.

\section{Pengaruh Implementasi Terhadap Kepuasan Pasien}

Sebelum melaksanakan tindakan yang sudah direncanakan perawat perlu memvalidasi dengan singkat apakah rencana tindakan masih sesuai dan dibutuhkan klien sesuai dengan kondisi saat ini. Perawat juga menilai diri sendiri, apakah mempunyai kemampuan interpersonal, intelektual, teknik sesuai dengan tindakan yang akan dilaksanakan. Proses Implementasi Pelaksanaan Keperawatan:

a. Pengkajian ulang terhadap klien

b. Meninjau dan merevisi rencana asuhan keperawatan

c. Mengorganisasi sumber daya dan pemberian asuhan

d. Mengantisipasi dan mencegah komplikasi.

e. Mengimplementasikan intervensi keperawatan 


\section{Kesimpulan}

Dalam memberikan asuhan keperawatan kita harus menggunakan proses keperawatan dimana bertujuan untuk memaksimalkan pelayanan terhadap pasien agar pasien merasa puas dengan tindakan yang diberikan.

Adapun tahap-tahap proses keperawatan yaitu Pengkajian, Diagnosis Keperawatan Perencanaan,Pelaksanaan dan Evaluasi karna setiap proses keperawatan mempunyai pengaruh baik positif ataupun negatif terhadap pasien. 


\section{DAFTAR PUSTAKA}

- Mohamad Kasim, Muh Abdurrouf. (2016). Peningkatan Kualitas Pelayanan Dan Pendokumentasian Asuhan Keperawatan Dengan Metode Tim. NurseLine Journal. Vol.1,No.1.

- Restu Ulfah, Madya Sulisno. (2012). Pengetahuan Tentang Konsep Keperawatan Holistik. Jurnal Nursing Studies, Vol.1,No.1.

- Wiwin Nur Aeni, Winani, DKK. (2019). Perilaku Caring Perawat Dalam Memberikan Asuhan Keperawatan Di Salah Satu RS Di Kabupaten Indramayu. Jurnal Keperawatan Profesional (JKT). Vol.7,No.2.

- Fatmawati Astar, Hesmin Tamsah, Ikhasan Kadir. Pengaruh Pelayanan Asuhan Keperawatan Terhadap Kepuasan Pasien Di Puskesmas Takalala Kabupaten Soppeng. Journal Of Management. Vol.1,No.2.

- Sumijatun. (2010). Konsep Dasar Menuju Keperawatan Professional. Jakarta:Trans Info Media.

- Hamzah, Thomas. (2016). Rancangan Bangun Sistem Dokumentasi Asuhan Keperawatan Bagi Tenaga Perawat Dalam Mendiagnosis Pasien. Vol.2,No.3.

- Wartonah, Tartowo. (2006). Kebutuhan Dasar Keperawatan dan Proses Keperawatan. Jakarta : Salemba Medika.

- Supranto, J. (2001). Pengukuran Tingkat Kepuasan Pelanggan: Untuk Menaikkan Pangsa Pasar, Jakarta, Rinneka Cipta.

- Nanda. 2015. Diagnosa keperawatan : Defenisi dan Klasifikasi 2015-2017 (10th ed). Jakarta: EGC

- Budiono. 2015. Konsep Dasar Keperawatan. Jakarta : Bumi Medika

- Simamora, R.H. (2019). Development Of Guidelines For Applying approriate Patient Identification to Achieve Patient Safety Goal INC2019 12th International Conference. 2019. 10 455-455 (1 Pages) UC (KEPA) . |410-ECN-0101-2019-512-001224337 